\title{
LABILITY OF ORGANIC GROUPS IN THE REACTION OF 2-(2- PYRIDYL)PHENYL(P-ETHOXYPHENYL)TELLURIUM(II) WITH PALLADIUM (II) AND PLATINUM (II) CHLORIDES.
}

\author{
SA Mbogo \\ Department of Chemistry, University of Dar es Salaam, \\ P.O. Box 35061, Dar es Salaam, Tanzania \\ Email : Mbogo@chem.udsm.ac.tz
}

\begin{abstract}
Reaction between 2- (- pyridyl )phenyl(p-ethoxyphenyl)tellurium(II), $\mathrm{RR}$ 'Te, and $\mathrm{PdCl}_{2}$ or $\mathrm{PtCl}_{2}$ are complex. The organic groups $R$ and $R$ ' are labile, trans-metallation to form RM-groups $(M=P d, P t)$ occurs. The solid phases isolated have well defined stoichiometries, eg $R$ 'TePdCl, $\mathrm{R}_{2} \mathrm{R}$ 'TePtCl${ }_{5}$ and these are discussed together with IR, ${ }^{1} \mathrm{H}$ and ${ }^{195} \mathrm{Pt}$ NMR data.
\end{abstract}

\section{INTRODUCTION}

Mercury telluride is an important semi conductor with application in infra-red detection (Charlon 1982, Mullin \& Irrine 1985). Photolysis of mixture of the organometallic compounds RHgTeR and RCdTeR can produce mercury cadmium telluride. Haris and Nissan (1987) prepared (t-butyl)HgTe(t-butyl) and demonstrated that it produces a film of mercury telluride upon photolysis in the gas phase. The synthesis and crystal structure of 2-(-pyridyl)phenyl (p-ethoxyphenyl)tellurium(II) have been reported (Al - Salim et al 1988). Subsequently two papers describing the interactions of the telluride with $\mathrm{HgCl}_{2}$ and with copper salts were published (Mbogo and McWhinnie 1990, Mbogo and Lobana 1991)

Both papers established lability of organic groups from tellurium on reaction with metal compounds. In the case of $\mathrm{HgCl}$ (Mbogo\& Mcwhinnie 1991) the reaction was clean:

$$
\mathrm{RR}^{\prime} \mathrm{Te}+2 \mathrm{HgCl}_{2} \rightarrow(\mathrm{RTeCl})_{2} \cdot \mathrm{R}^{\prime} \mathrm{HgCl}+\mathrm{RHgCl}
$$

(where $\mathrm{R}=2$-(2-pyridyl)phenyl and $\mathrm{R}^{\prime}=$ p-ethoxyphenyl)

An $X$-ray crystallographic investigation of (A) reveals six molecules in the unit cell $2 x$ (2RTeCl.R'HgCl) but no signification intermolecular interactions are present (Mbogo et al 1992). With copper halides the reactions were much less clean but clear evidence for lability of organic groups was found (Mbogo and lobana 1991). Since (Pathirina \&Mcwhirinie 1988) Kemnitt et al 1992) have also observed labilisation of tellurium bonded organic group when tellurides co-ordinate platinum(II) and considering the significance of the observed phenomenon in relation to Metal-Organic Chemical Vapour Deposition (MOCVD), it was decided to extend studies of RR'Te coordination behavior to palladium(II) and platinum(II). The results of these investigations are briefly presented:

\section{MATERIALS AND METHODS}

2-(2-pyridyl)phenyl(pethoxyphenyl)telluride, RR'Te and 2-(2pyridyl) phenyltellurium (II) bromide, $\mathrm{RTeBr}$, were prepared following the literature (Charlton 1982) 


\section{Synthesis of palladium complexes. Complex 1}

Palladium dichloride $(0.09 \mathrm{~g}, 0.5 \mathrm{mmol})$ in acetonitrile $\left(10 \mathrm{~cm}^{3}\right)$ was heated to reflux under nitrogen. RR,Te $(0.2 \mathrm{~g}, 0.5 \mathrm{mmol})$ in acetonitrile $\left(10 \mathrm{~cm}^{3}\right)$ was added. The mixture was cooled to room temperature and the contents of the flask were stirred for $15 \mathrm{~min}$. A dark brown compound separated out. The product was filtered, washed with acetonitrile and dried in vacuo over $\mathrm{P}_{4} \mathrm{O}_{10}$ to give compound (1) in $48 \%$ yield, m.p 197$199{ }^{\circ} \mathrm{C}(\mathrm{dec})$

\section{Complex 2}

2-(2-pyridyl)phenyltellurium(II)bromide, $\mathrm{RTeBr}(0.18 \mathrm{~g}, 0.5 \mathrm{mmol})$ in acetonitrile $\left(10 \mathrm{~cm}^{3}\right)$ was added to a refluxing solution of palladium dichloride $(0.09 \mathrm{~g}, 0.5 \mathrm{mmol})$ in acetonitrile $\left(10 \mathrm{~cm}^{3}\right)$ under nitrogen. The reaction mixture was refluxed for $1 \mathrm{hr}$. A brown precipitate formed which was separated, washed with acetonitrile and dried in vacuo over $\mathrm{P}_{4} \mathrm{O}_{10}$ to give compound (2) in 52\% yield, m.p $245-247^{\circ} \mathrm{C}$ (dec)

\section{Synthesis of platinum complexes Complex 3}

RR'Te $(0.20 \mathrm{~g}, 0.5 \mathrm{mmol})$ in acetonitrile $\left(10 \mathrm{~cm}^{3}\right)$ was added to a refluxing solution of platinum dichloride $(0.13 \mathrm{~g}, 0.5 \mathrm{mmol}))$ in acetonitrile $\left(10 \mathrm{~cm}^{3}\right)$ under nitrogen. The colour changed immediately to red. The mixture was stirred at room temperature for $30 \mathrm{~min}$ and filtered. Ethanol was added to the filtrate and a red precipitate formed which was filtered, washed with acetonitrile and dried in vavuo to give compound (3) in $58 \%$ yield, m.p $210-211^{\circ} \mathrm{C}$

\section{Complex 4}

$\mathrm{RTeBr}(0.18 \mathrm{~g}, \quad 0.5 \mathrm{mmol})$ in acetonitrile $\left(10 \mathrm{~cm}^{3}\right)$ was added under nitrogen, to refluxing platinum dichloride $(0.13 \mathrm{~g}$, $0.5 \mathrm{mmol})$ in acetonitrile $\left(10 \mathrm{~cm}^{3}\right)$. The mixture was refluxed for $1 \mathrm{~h}$. The yellow precipitate was filtered and dried in vacuo over $\mathrm{P}_{4} \mathrm{O}_{10}$ to give compound (4) in $52 \%$ yield, m.p $260-261^{\circ} \mathrm{C}$

\section{Physical measurements}

${ }^{1} \mathrm{H}$ and ${ }^{125} \mathrm{Te}$ NMR spectra were determined with a bruker AC $300 \mathrm{MHZ}$ spectrometer at 300 and 94.7MHZ, respectively. Tetramethyl silane was used as the reference for ${ }^{1} \mathrm{H}$, for ${ }^{125} \mathrm{Te}$ the reference was bis - (pethoxyphenyl)ditelluride (external) in $\mathrm{CDCl}_{3}$ which has $\delta=456 \mathrm{ppm}$ w.r.t $\mathrm{Me}_{2} \mathrm{Te}$, with respect to which all tellurium shifts are cited. ${ }^{195} \mathrm{Pt}$ NMR measurements were at 64.52 MHZ, the reference was aqueous $\mathrm{Na}_{2}(\mathrm{PtCl})_{6}$ (external ).

Routine IR studies were on $\mathrm{KBr}$ discs with a Perkin Elmer 1710 FT-IR instrument. Melting points were determined with a Gallen Kamp electrically heated apparatus.

\section{RESULTS AND DISCUSSION}

The reaction of the ligand RR'Te $(R=2-(2-$ pyridyl)phenyl, R' = p- ethoxyphenyl)

With palladium(II) and platinum(II) halides gave compounds with stoichiometrie's as shown in Table 1.

Table 1: Empirical formulae of complexes, analytical data and melting points

\begin{tabular}{|c|c|c|c|c|c|c|c|c|c|}
\hline \multirow[t]{2}{*}{ Complex } & \multirow[t]{2}{*}{ Empirical formula } & \multirow[t]{2}{*}{ Colour } & \multirow[t]{2}{*}{$\begin{array}{l}\text { Melting } \\
\text { point }{ }^{\circ} \mathrm{C}\end{array}$} & \multicolumn{3}{|c|}{ Found $\%$} & \multicolumn{3}{|c|}{ Calculated \% } \\
\hline & & & & $\mathrm{C}$ & $\mathrm{H}$ & $\mathrm{N}$ & $\mathrm{C}$ & $\mathrm{H}$ & $\mathrm{N}$ \\
\hline 1 & R'ClPdTe & Dark brown & $197-199(\mathrm{dec})$ & 24.6 & 2.19 & 0.00 & 24.6 & 2.30 & 0.00 \\
\hline 2 & $\mathrm{PdCl}_{2 .}(\mathrm{RTeBr})_{2} \mathrm{MeCN}$ & brown & $245-247(\mathrm{dec})$ & 28.9 & 1.95 & 3.65 & 28.4 & 1.89 & 3.79 \\
\hline 3 & $\mathrm{R}^{\prime} \mathrm{TeCl} .\left(\mathrm{RPtCl}_{2}\right)_{2}$ & red & $210-211$ & 32.0 & 2.7 & 2.42 & 32.0 & 2.23 & 2.49 \\
\hline
\end{tabular}




\begin{tabular}{llllllllll}
\hline 4 & $\mathrm{PtCl}_{2} \cdot(\mathrm{RTeBr})_{2}$ & yellow & $260-263$ & 26.8 & 1.55 & 2.9 & 26.1 & 1.6 & 2.82
\end{tabular}

\section{Palladium complexes}

For the reaction of palladium dichloride with RR'Te, a coordination compound (1) is formed with complete loss of the $(\mathrm{R}=2-(2-$ pyridyl)phenyl) group for tellurium as represented by the equation below:

$$
\mathrm{RR}{ }^{\prime} \mathrm{Te}+\mathrm{PdCl}_{2} \rightarrow \mathrm{R}^{\prime} \mathrm{TePdCl}+\mathrm{RCl}
$$

This formulation is supported by IR, NMR and elemental analysis.

The infrared spectrum showed a single $\gamma$ (Pd-Cl) at $339 \mathrm{~cm}^{-1}$ comparative to that observed

[PdCl.RTe $\left.\left(\mathrm{CH}_{2}\right)_{8} \mathrm{TeR}\right]($ Pathirina

for

Mcwhinnie 1988).

The elemental analysis shows the $\% \mathrm{~N}$ to be "nil" hence formulation R' $\mathrm{TePdCl}$, with no $\mathrm{R}$ groups. The HNMR spectrum in dime thyl sulphoxide (DMSO) reveals one environment for R' groups consistent with the formulation. The ${ }^{125} \mathrm{Te}$ NMR spectrum (DMSO) shows a single resonance at $\delta=$ 1057.9 ppm (cf. free ligand. (RR'Te), 649.1 $\mathrm{ppm}$ ). This chemical shift is well outside the range reported in telluride (Irgolic et al 1983) In the compound ( $\left.\mathrm{R}^{\prime} \mathrm{HgCl}\right)(\mathrm{RTeCl})_{2}$ prepared by (Mbogo \& McWhinnie) 1991), it was found that ${ }^{125} \mathrm{Te}$ NMR spectrum showed a single resonance at $\delta=1323.9$ $\mathrm{ppm}$, a figure supporting the presence of $\mathrm{RTeCl}$ species.

Interestingly, the ${ }^{125} \mathrm{Te}$ NMR spectrum of complex (2), a product formed from the reaction of $\mathrm{RTeBr} \quad(\mathrm{R}=2$-(2-pyridyl) phenyl) with $\mathrm{PdCl}_{2}$ gave two resonances a major at $\delta=1315.7 \mathrm{ppm}$ typical of tellurenyl halide (Ahmed et al 1986), but a minor resonance $\delta=1297.7 \mathrm{ppm}$ is also noted. The two peaks are believed to be due to coordination by DMSO. It would thus appear that both $\mathrm{R}$ and $\mathrm{R}^{\prime}$ are very labile in the presence of palladium(II) chloride.

\section{Platinum complexes}

A similar pattern emerges as for palladium. Complex (3) is worth of specific comment since the C:N ration (15:4:1) is identical to that of the well defined reported material $(\mathrm{RTeCl})_{2}\left(\mathrm{R}^{\prime} \mathrm{HgCl}\right)$ (Mbogo \& McWhinnie 1991).

The complex was sparingly soluble in $\mathrm{CDCl}_{3}$, a ${ }^{1} \mathrm{H}$ NMR spectrum was obtained (but not ${ }^{125} \mathrm{Te}$ or ${ }^{195} \mathrm{Pt}$ spectra due to limited solubility). The ${ }^{1}$ HNMR spectrum of the complex in $\mathrm{CHCl}_{3}$ shows broadening of the peaks in the aromatic region whereas the peaks in the alphatic region are well resolved and sharp. A triplet signal centered at $\delta=1.40 \mathrm{ppm}$ is assigned to $-\mathrm{CH}_{3}$ protons and a quartet centered at $\delta=3.88 \mathrm{ppm}$ is assigned to $-\mathrm{CH}_{2}$ protons.

In particular, two distinct resonances arising from the protons ortho to the pyridly nitrogen atoms were seen at $\delta=9.51$ and $9.98 \mathrm{ppm}$.

In summary, it appears that these very complex system created from the reaction of RR'Te with $\mathrm{MCl}_{2}(\mathrm{M}=\mathrm{Pd}, \mathrm{Pt})$ involve labile organic groups ( $\left.\mathrm{R}^{\prime} \mathrm{R}\right)$ and transmetallation to form RM-groups.

This observation highlights the potential usefulness of tellurides with particularly labile organic groups as precursors for the Metal Organic Chemical Vapour Deposition ( MOCVD) of both main group and transitional metal chalcogenides.

\section{ACKNOWLEGMENTS}

The author thanks NORAD and Sida/SAREC for financial support.

\section{REFERENCES}

Ahmed AK, McCarthy AE, McWhinnie WR and Berry FJ 1986 Synthesis and reaction of $1,2-\operatorname{Bis}(\mathrm{p}$ - 
ethoxyphenytelluromethyl)benzene with Palladium and Platinum chlorides. $J$.

organomet. Chem.. 312: 323-327

Al-Salim NF, West AA and McWhinnie WR 1988 Crystal structure of 2-(2pyridyl)phenyl(p-

ethoxyphenyl)tellurium(II) J. Chem. Soc. Dalton Trans. 2363-2369.

Harris CD and Nissan RA 1987 Photolysis of Organometallic compounds RHgTeR and RCdTeR Inorg. Chim. Acta 69: 203215

Kemnitt T, Levason W, Spicer D and Webster M 1992 New Organotellurium ligands. J. Organomet. Chem 9: 1181 1185

Mbogo SA and McWhinnie WR 1990 The reaction of 2-(2-pyridyl)phenyl(p-
ethoxyphenyl)tellurium(II) with mercury (II) chloride; a case of reverse transmetallation. J. Organomet Chem. 384: 115-119.

Mbogo SA and Lobana TS 1991 The Reactivity of 2-(2-pyridyl)phenyl(pethoxyphenyl)tellurium(II) towards Copper(I) and Copper(II) Halides. Inorg. Chim. Acta. 172: 221-224.

Mbogo SA, McWhinnie WR and Lobana TS 1992 The crystal structure of compound $\left[\mathrm{R}^{\prime} \mathrm{HgCl}(\mathrm{RTeCl}){ }_{2}^{2}\right]$. Journal of Organomet. Chem. 391: 244-249.

Pathirina HM and McWhinnie WR 1988 The Co-ordination chemistry of Bidentate Tellurium Ligands; Complexes of Palladium, Platinum with large chelate Rings. Inorg. Chim. Acta 143:161-167. 